\section{2nd EPS Topical Workshop in Applied Physics}

The second in the series of Workshops aimed primarily at the Associate Members of EPS, following the one on Pyroelectric Arrays held from 26 to 29 April 1987 is on:

The Future of Magnetic-

Optic Recording.

The place is again Bad Honnef, FRG and the date is 2-4 November 1987.

Organising the Workshop are: Prof. $\mathrm{H}$. Hoffman, Universität Regensburg, and Prof. S. Methfessel, Ruhr Universität, Bochum from either of whom further information on the scientific programme can be obtained. For information on the practical details of attending, contact the EPS Secretariat. The numbers will be limited to about 40 and although Associate Members will have priority, the meeting is open to others.

The Workshop is designed to examine the implications of the recent ascendancy of optical recording over magnetic tapes, made obvious to everyone by modern disk players. Great investments are now being made world-wide in research and the development of better magneto-optical materials, new light sources and other devices, which may be suitable for the design of erasable high density optical memories in data processing or for optical computers. This scientific and technical challenge certainly exceeds the resources and market capacity of any individual country in Europe and an effective international collaboration in this field becomes an essential prerequisite for success.

The Workshop will bring together leading experts from industry and universities in order to contemplate and discuss during three days, in the relaxed atmosphere of the Physikzentrum in Bad Honnef, the potential and future of magneto-optic recording and its relevance to the market place. They may find special areas of interest and strength, where outstanding progress in the field can be expected from the collaboration between industry and universities in Europe.

Tentative topics are: System aspects, Materials, Light sources, Future technologies, Market aspects, Unconventional approaches (e.g. holography).

The Associate Members have been invited to make recommendations for contributors and Session Chairmen; intention to participate should be notified to the EPS Secretariat before the end of May if that is at all possible.
European Organization for Nuclear Research

Organisation Européenne pour la Recherche Nucléaire

European Laboratory for Particle Physics

Laboratoire Européen pour la Physique des Particules

The Experimental Physics Division intends to make an appointment to the position of

\section{PHYSICIST}

in experimental particle physics research. Candidates are expected to have an excellent record of successful work in this field, and to have the ability to provide leadership. Preference will be given to candidates under 38 years of age. The appointment will be made for a fixed term, and may subsequently become permanent.

The holder will play an important role in all aspects of the conception and design of experiments, and of the construction and operation of detectors, and the development of on-line and off-line software and the analysis of data.

Please send letters of application, including the names of three referees, list of publications, a brief curriculum vitae and a brief description of research interests before 15 June 1987 to the:

\section{Leader of the Experimental Physics Division, CERN 1211 Geneva 23, Switzerland}

quoting reference EP/RE.

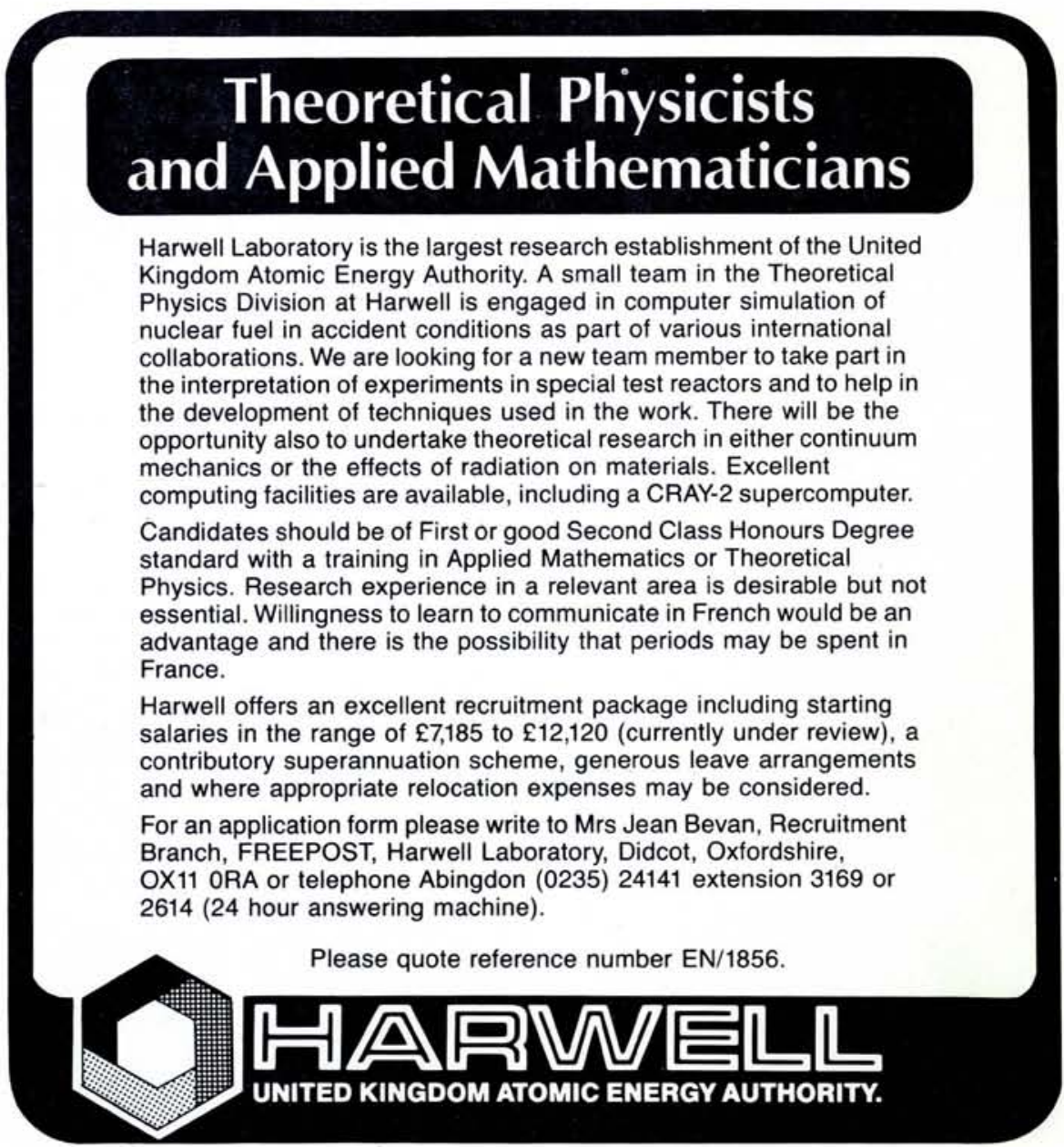

